\title{
On the relationship between medical ethics and medical professionalism
}

The Journal of Medical Ethics strongly encourages contributions from medical students, and is one of the very few journals that retain a separate section for publishing student papers. Reflecting our desire as editors to showcase rigorous analyses of practically relevant ethical issues in healthcare, students are often ideally placed to identify novel concerns that may have been taken for granted by more senior colleagues, and to put forward ethical arguments that are acutely sensitive to the day-to-day realities of practice in which they are learning their trade.

In this issue, the ethical reflections by a student on what might seem a rather innocuous act-kissing the head of a child patient to console him after a failed attempt at cannulation-reveals some challenging questions about what it means to act professionally in a healthcare role. The article by Alamri (see page 636) and the accompanying commentary by Kerruish and Anderson (see page 638) develop arguments and counter-arguments that connect a number of points about whether such behaviours are acceptable when they take place between a healthcare professional and a child patient. One point that is immediately striking when beginning to analyse this issue is the relationship between a claim about the ethics of kissing the patient, and a broader claim about the student's professionalism. We might disagree about whether giving the patient a kiss would be ethically justifiable. Equally, we might disagree about whether such a behaviour could ever be justifiable when performed by a healthcare professional, even if we broadly agree that it was ethically defensible to kiss the patient in this instance.

This relationship between ethics and professionalism in healthcare is a complex one, as the analyses of this case illustrate. However, despite such complexity, there is a growing trend (particularly within medical education) to conflate these two concepts. It is not uncommon to find medical ethics curricula expanding to include professionalism as an additional body of knowledge that should be taught to medical students

Correspondence to Michael Dunn, Department of Ethox Centre, University of Oxford, Headington, Oxford, OX3 7LF, UK; michael.dunn@ethox.ox.ac.uk alongside medical ethics by medical ethicists. Equally, there have been recent developments in the UK by the medical regulator, the General Medical Council (GMC), that seek to foreground professionalism as a key focus for medical education, ${ }^{34}$ with medical schools taking very different approaches to developing professionalism alongside ethics as an integrated or distinct educational track. It is important, therefore, to get clear on how medical ethics and medical professionalism interconnect. Providing clarity about this relationship in the medical education context can also assist in clarifying how ethical and professionalism claims relate when they are invoked to analyse ethical issues in medical ethical scholarship of the kind presented in this issue.

One way in which the relationship between ethics and professionalism might be understood is to claim equivalence between the two concepts. Understanding professionalism as the straightforward recasting of ethics would make most sense in the context of medical education where it would operate as little more than a marketing strategy. This strategy could be justified by observing that there can, on occasion, be the misperception amongst medical educators and students that ethics education involves little more than reflecting on cases in ways that take into account the different values held by individuals in the classroom. Labelling ethics as professionalism in medical training environments makes it absolutely clear that medical ethics is a particular kind of professional ethics; that students (and indeed their more senior colleagues) need to grasp the specific duties they have within their professional role as doctors, and that they need to be equipped to make judgements that invoke these duties in practical decision-making contexts.

One immediate concern is that, in the recasting process, the content of medical ethics itself is reformulated in ways that undermine its core purpose and value. The GMC's recent professionalism drive in medical education risks erring in this way if it is not implemented carefully by medical educationalists. Much of the motivation for placing professionalism at the centre of students' education looks to be derived from the belief that students are not behaving as they ought, and that it is important to maintain standards of professional behaviour and fitness to practice. The risk here is that medical professionalism reinforces the idea that ethics education ought to be narrowly focused on ensuring that medical students behave in ways that comply with the standards set by the professional regulator, and in line with broader legal requirements. Whilst it is of course important to ensure that students recognise which actions are lawful and unlawful, acceptable and unacceptable, and that they behave accordingly, the requirements of medical law and professional guidance largely incorporate sufficiently flexibility to allow students to reason between competing values and to make practical judgements that are defensible on ethical grounds. Equally, abandoning the focus on fostering ethical sensitivity and reasoning skills in medical students in order to ensure that students simply know the basics of what they are permitted to do, would be to neglect our responsibilities as educators in this setting.

In contrast with interpreting professionalism in terms of compliance, a more contentful approach to making sense of professionalism is to take seriously the idea that professional role morality, enacted and performed as it is in a variety of socially and institutionally diverse settings, is one that needs to be fostered in ways that extend beyond merely exposing students to knowledge about the ethical duties that apply to their practice. As Buyx and colleagues (2008) argue persuasively, ${ }^{2}$ this focus on the importance of inculcating professional role morality as a central component of medical education gives rise to new foci: i) the explicit fostering of personal attributes (or virtues) that are recognised as being crucial to students' forging their identity and behaviours as healthcare professionals, and, ii) the development of personal strategies of resilience that enable students to maintain such attributes when buffeted by the different psychological, social, economic and moral challenges that arise in their varied workplaces and across their careers. Buyx et al. (ibid) advance i) fidelity to trust, ii) benevolence, iii) compassion, iv) intellectual honesty, v) courage, and vi) truthfulness as those virtues that are widely accepted as being constitutive of role morality in medicine. 
This account looks correct, but is still far from clear precisely how professionalism, understood in this way, relates to the work that medical ethicists are engaged in. Much will depend here on how background disagreements in moral philosophy between virtue-based and duty-based accounts of ethics are resolved. One strategy might be to substitute these virtues for standard accounts of ethical duties (the duty to respect autonomy; the duty to act beneficently etc.). Another strategy might be to draw upon these virtues to expand the range of ethical duties that underpin good practice in healthcare-perhaps through statements of principles for professional behaviour, as Kerruish and Anderson attest to when they cite the work of the American Academy of Paediatrics (2007). In my view, both of these strategies ought to be resisted. On the first strategy, to act ethically would be to act in ways that demonstrate the relevant attributes, for example that in acting honestly, courageously, and with compassion one is behaving ethically in one's professional role. This would underdetermine ethical decision-making and behaviour in healthcare, with commonly-accepted obligations owed to respect patients and to further their interests being largely absent from ethical discourse. On the second strategy, virtues such as compassion, courage and intellectual honesty would be placed alongside other ethical obligations in health care. This approach fails to recognise that such virtues are dispositional traits, rather than values that are directly relevant to practical ethical decision-making, and that therefore cannot be traded off against each other when making ethical judgements in specific cases. It would, for example, be a mistake to equate the requirement to be courageous or to be compassionate as a duty of the same kind as, for example, the duty to respect a patient's autonomy.

A more coherent approach, I think, is to recognise that the virtues that are constitutive to medical role morality in establish the preconditions that enable doctors to develop and apply the clinical skills they need. Such skills include the ability to recognise, to reason carefully between, and to enact the ethical duties that are endorsed as underpinning good medical practice. In this sense, the inculcation of such virtues is a necessary but not sufficient condition for making ethical judgements as a doctor. One cannot act ethically if one is not a professional who has fostered the correct attributes-compassion, honesty, courage etc.-but being a compassionate, honest and courageous professional provides no guarantee that one will act ethically.
Where does that leave the role of the medical ethicist in contributing to medical professionalism? As Buyx and colleagues (ibid) articulate, understanding professionalism in this way challenges the idea that the medical ethicist ought to take the lead in teaching professionalism. Why think, for example, that a medical ethicist will be appropriately skilled or remotely best-placed to help medical students become more compassionate or more courageous in the workplace? Precisely where and how professionalism ought to feature in medical schools remains an important and inadequately addressed question. Notwithstanding this broad observation, medical ethicists should retain discernible roles in relation to professionalism. They will be well placed to help to determine which virtues ought to be recognised a being core to the exercise of medical role morality. Ethicists are, by and large, equipped with the conceptual apparatus that will be crucial to ensuring that these virtues are specified accurately. Equally, there will be space in medical ethics classrooms to help students to recognise the link between professional virtues and the exercise of their ethical duties towards patients and others. For example, medical ethicists might explore with students how the virtue of intellectual honesty impacts on the ability to calculate patients' objective and subjective interests in a robust manner, or how a compassionate approach to patient care functions to enhance a doctor's ability to respect the patient as a person.

So far so good. There is, however, one residual concern emanating from this strict separation between ethics and professionalism. Such an account renders incoherent the claims that I introduced at the start of this editorial, namely that a doctor or medical student can act ethically but unprofessionally. This does not seem quite right. How then can we square this particular circle? Perhaps the solution lies in recognising that our focus as medical ethicists on normative issues in healthcare incorporates broader questions about the exercise of one's role morality that is not limited to reasoning about the ethical duties that are internal to that role. In addition to determining how health professionals ought to act in the face of competing ethical obligations, these professionals must also determine when they are permitted to set aside their professional duties on the basis of other obligations: obligations to themselves, obligations to their loved ones, obligations to their employers, obligations to their peers, etc. Like most medical ethical challenges, this kind of professionalism challenge is a distinctly normative one, and would relate to circumstances that include the appropriate exercise of conscientious objection, whistleblowing or raising concerns, or participating in strike action as part of an employment dispute.

To summarise then, medical professionalism is rightly understood as relevant to medical ethics, but only because professionalism concerns those virtues or attributes that foster health practitioners' abilities to recognise, interrogate, and to enact the ethical duties they possess in their roles. Understanding the relationship between ethics and professionalism in this way also helps to ensure that a broader category of ethical concerns relating to professional behaviour in medical practice is made the requirement to address moral issues in healthcare practice that arise out of a tension between the exercise of well-recognised medical ethical duties and competing obligations that professionals have to themselves and to others).

Returning to the arguments presented by Alamri and by Kerruish and Anderson, this distinction between two different kinds of practical 'ought' questions-one medical ethical and one medical professional—can assist in diagnosing precisely what might be at issue in the case of the student kissing his child patient. In relation to the medical ethical question, it needs to be determined whether the interests of the child were best served by kissing the child in this way, or if duties owed by the student to the child's patients were undermined by this behaviour. There is disagreement between the author and commentator on this point that needs to be settled. In relation to the medical professionalism question, there are questions about whether kissing the patient was an appropriate foregrounding of the student's own interests or concerns (gaining closure after a difficult learning experience), or whether this behaviour was an instance where dominant socio-cultural values should be taken to transcend the exercise of one's professional duties, therefore rendering the kiss justifiable. Like Kerruish and Anderson, I am sceptical that either of these questions would be resolved in favour of the behaviour in question, and so remain unconvinced that kissing the child was justifiableon both ethical and professional grounds.

\section{REFERENCES}

1 American Academy of Pediatrics, Fallat ME, Glover J. Professionalism in pediatrics: statement of principles. Pediatrics 2007; 120:895-7

2 Buyx AM, Maxwell B, Schone-Seifert B. Challenges of educating for medical professionalism: who should step up to the line? Medical Education. 2008;42:758-64.

3 GMC. Good Medical Practice. London: General Medical Council, 2013

4 GMC. Professional Behaviour and Fitness to Practice: Guidance for medical schools and their students. London: General Medical Council, 2016. 